\title{
Simvastatin ameliorates ionizing radiation-induced apoptosis in the thymus by activating the AKT/sirtuin 1 pathway in mice
}

\author{
HONG YANG $^{1 *}$, FEI HUANG ${ }^{1 *}$, YULONG TAO $^{1 *}$, XINBIN ZHAO $^{2}$, LINA LIAO $^{1}$ and XIA TAO ${ }^{1}$ \\ ${ }^{1}$ Department of Pharmacy, Shanghai Changzheng Hospital, Second Military Medical University, Shanghai 200003; \\ ${ }^{2}$ School of Pharmaceutical Sciences Medicine, Tsinghua University, Beijing 100084, P.R. China
}

Received February 1, 2016; Accepted June 20, 2017

DOI: $10.3892 /$ ijmm.2017.3047

\begin{abstract}
Simvastatin is a $\mathrm{HMG}-\mathrm{CoA}$ reductase inhibitor widely used to lower plasma cholesterol and to protect against cardiovascular risk factors. The aim of this study was to investigate whether simvastatin attenuates ionizing radiation-induced damage in the mouse thymus and to elucidate the possible mechanisms invovled. For this purpose, male C57BL/6J mice aged 6 weeks were used and exposed to $4 \mathrm{~Gy}$ ${ }^{60} \mathrm{Co} \gamma$-radiation with or without simvastatin $(20 \mathrm{mg} / \mathrm{kg} / \mathrm{day}$, for 14 days). Apoptosis was determined by terminal deoxynucleotidyltransferase-mediated dUTP nick-end labeling (TUNEL) assay or transmission electron microscopy (TEM) examination. Thymocytes were also isolated and incubated in DMEM supplemented with $10 \% \mathrm{FBS}$ at $37^{\circ} \mathrm{C}$ and exposed to $8 \mathrm{~Gy}$ ${ }^{60} \mathrm{Co} \gamma$-radiation with or without simvastatin $(20 \mu \mathrm{M})$. The expression levels of Bcl-2, p53, p-p53, AKT, sirtuin 1 and poly(ADP-ribose) polymerase (PARP) were determined by western blot analysis. TUNEL and TEM examination revealed that simvastatin treatment significantly mitigated ionizing radiation-induced apoptosis in the mouse thymus. It was also found that simvastatin treatment increased AKT/ sirtuin 1 expression following exposure to ionizing radiation in vivo and in vitro. In the in vivo model, but not in the in vitro model, Bcl-2 and PARP expression was augmented and that of p53/p-p53 decreased following treatment with simvastatin. On the whole, our findings indicate that simvastatin exerts a protective effect against ionizing radiation-induced damage in the mouse thymus, which may be partially attributed to the activation of the AKT/sirtuin 1 pathway.
\end{abstract}

Correspondence to: Professor Xia Tao, Department of Pharmacy, Shanghai Changzheng Hospital, Second Military Medical University, 415 Feng-yang Road, Shanghai 200003, P.R. China

E-mail: taoxia2003@126.com

*Contributed equally

Key words: simvastatin, ionizing radiation, thymus, apoptosis, AKT/sirtuin 1

\section{Introduction}

Ionizing radiation (IR) carries energy strong enough to ionize atoms and molecules, and break chemical bonds. Radiotherapy is a widely used antitumor strategy and accounts for $25 \%$ of cancer therapy (1). However, IR can break important biomolecules, such as DNA, damaging or killing the affected cell (2). Apart from its anti-proliferative and cell-killing effects in tumor tissue, radiotherapy provokes severe damage to normal tissue $(3,4)$.

The mechanisms of IR-induced tissue damage are complex; however, one of the main mechanisms is DNA damage-related, and another is DNA damage-unrelated (4). Downstream pathways from those two starts are cross-linked, forming an IR-induced signaling network (5). This network involves two major terminals: apoptosis and inflammation (6-8). The p53-mediated apoptotic pathway is the most acclaimed mechanism of radiation-induced damage (9). Protein 53 (or tumor protein 53) is crucial in multicellular organisms, functioning as a tumor suppressor involved in the prevention of cancer $(10,11)$. B-cell lymphoma $2(\mathrm{Bcl}-2)$ is the founding member of the Bcl-2 family of regulator proteins that regulate cell death and apoptosis (12-14). Human p53 can activate the apoptotic effectors, BAX or BAK, resulting in mitochondrial outer-membrane permeabilization and apoptosis, which can be opposed by the anti-apoptotic protein, Bcl-2 $(15,16)$.

AKT is a serine/threonine-specific protein kinase that plays a key role in multiple cellular processes, such as apoptosis and cell proliferation. AKT activation has been recognized as a crucial player in IR-induced apoptosis $(17,18)$. A previous study demonstrated that mice with homozygous disruption of AKT exhibited growth retardation and increased spontaneous apoptosis in tissues, such as the thymus (19). Silent mating type information regulator 2 homolog 1 (sirtuin 1), a histone deacetylase, has various biological activities, including the extension of lifespan (20). A recent study demonstrated that sirtuin 1 plays an essential role in the regulation of AKT activation (21). Furthermore, it has been reported that the upregulation of sirtuin 1 is closely linked to AKT activation (22).

Poly(ADP-ribose) polymerase (PARP) is a family of proteins which play a role in a number of cellular processes involving mainly DNA repair and programmed cell death (23). Activated PARP can deplete the ATP of a cell in an attempt to repair the damaged DNA. ATP depletion in a cell leads to lysis and cell death (necrosis) (24). In response to DNA damage 
caused by IR, PARP binds to strand interruptions in DNA and undergoes rapid auto-modification (25-28).

Simvastatin, a member of the statin (or HMG-CoA reductase inhibitors) class, is a lipid-lowering drug used to control elevated cholesterol, or hypercholesterolemia. It has been reported that statins exert pleiotropic effects on cellular stress responses, proliferation and apoptosis both in vitro and in vivo $(29,30)$. Our previous study found that simvastatin significantly ameliorated IR-induced morphological damage and apoptosis in the mouse jejunum and bone marrow (31). Notably, simvastatin also significantly attenuated IR-induced apoptosis in the mouse thymus. Individuals exposed to radiation exhibit a significant loss of peripheral immune cells (7). Since the thymus is a vital organ in the immune system, we selected the thymus to be the focus of the present study.

In this study, we examined whether simvastatin protects the mouse thymus from IR-induced damage in vivo and in vitro, and explored the possible mechanisms underlying the radioprotective effects of simvastatin.

\section{Materials and methods}

Mice and thymocytes. Male ( $\mathrm{n}=40)$ C57BL/6J mice (Sino-British Sippr/BK Laboratory, Shanghai, China), 5-7 weeks of age and weighing 18-22 g, were used for all animal experiments. The mice, housed in a local animal housing facility under controlled conditions (temperature, $21 \pm 2^{\circ} \mathrm{C}$; lighting, 8:00-20:00), received a standard mouse chow and tap water ad libitum. All animals received humane care, and the experimental procedures were in compliance with the institutional animal care guidelines. All the experiments were performed in a random and blind manner. All the experiments were approved by the local animal management and ethics committee. Thymocytes were isolated from C57BL/6 mice and cultured in Dulbecco's modified Eagle's medium (DMEM) supplemented with $6 \%$ fetal bovine serum (FBS) and $25 \mathrm{mM}$ HEPES (pH 7.2) and adjusted to a density of $1 \times 10^{6} /$ well for incubation at $37^{\circ} \mathrm{C}$. The relative amounts (approximately $85 \%$ ) of $\mathrm{CD}^{+} \mathrm{CD}^{+}$thymocytes were determined at various times by FACS analysis.

Experimental groups. Simvastatin was purchased from Sigma-Aldrich (Shanghai, China). The mice were randomly separated into 4 groups with 10 mice in each group as follows: the control $(\mathrm{C})$, simvastatin $(\mathrm{S})$, radiation $(\mathrm{R})$ and radiation + simvastatin (RS) group. Simvastatin $(20 \mathrm{mg} / \mathrm{kg} /$ day $)$ was pre-administrated in gavage for 14 consecutive days in the $\mathrm{S}$ and $\mathrm{RS}$ groups, while mice in $\mathrm{C}$ and $\mathrm{R}$ groups were administered the vehicle $(0.5 \% \mathrm{CMC} \mathrm{Na})$. The mice in the $\mathrm{R}$ and $\mathrm{RS}$ groups endured $4 \mathrm{~Gy}{ }^{60} \mathrm{Co} \gamma$-radiation. On 1, 3 and 7 days following radiation, the mice were sacrificed for the analysis of IR-induced thymus damage and the expression of related targets in the thymus. For cell analysis, the thymocytes were isolated as previously described (9). Briefly, thymocytes were isolated from a mouse aged 6 weeks in DMEM supplemented with 5\% FBS and $25 \mathrm{mM}$ HEPES (pH 7.2) and adjusted to a density of $1 \times 10^{6} / \mathrm{ml}$. Simvastatin at $20 \mathrm{mM}$ was added to the thymocytes $3 \mathrm{~h}$ prior to exposure to $8 \mathrm{~Gy}{ }^{60} \mathrm{Co} \gamma$-radiation.

Morphological examination. Following sacrifice, the jejuna and femurs of the mice were immersed in a $4 \%$ solution of paraformaldehyde in phosphate-buffered saline (PBS) and were fixed in this solution for $24 \mathrm{~h}$. The obtained jejunum segments were dehydrated in serial alcohol solutions, while the femurs were decalcified using Calci-Clear Rapid (SG HS-105; National Diagnostics, Atlanta, GA, USA). Tissues were embedded in paraffin, cut into $5-\mu \mathrm{m}$-thick sections, and stained with hematoxylin and eosin (H\&E) for light microscopic investigation (IX-71; Olympus, Tokyo, Japan). These sections were subsequently used to determine villus length $(\mathrm{mm})$. The length was calculated as follows: the value measured using a ruler was divided by the magnification of the image. One slide per mouse was used and the average values were taken for a minimum of 5 villi.

Weight measurement of thymi and spleens. Following sacrifice, the thymi and spleens were extracted from the mice. The weight of each organ was measured using an analytic balance (ALB224, Acculab) and recorded. The relative organ weight was calculated as the absolute weight divided by body weight of the corresponding mouse. The fold of control in each group was then attained for statistical analysis.

Terminal deoxynucleotidyltransferase-mediated dUTP nickend labeling (TUNEL) assay. Apoptosis in the thymus was analyzed by TUNEL staining in accordance with the instructions of an in situ cell death detection kit (Roche, Mannheim, Germany). In brief, paraffin-embedded sections of the tissues were first deparaffinized in gradient xylene/ethanol and digested for $15 \mathrm{~min}$ with $20 \mu \mathrm{g} / \mathrm{ml}$ proteinase $\mathrm{K}$ in $10 \mathrm{mM}$ Tris- $\mathrm{HCl}$ buffer ( $\mathrm{pH}$ 7.4). The samples were then incubated with terminal deoxyribonucleotidyl transferase enzyme (4810-30-05; R\&D Systems Minneapolis, MN, USA) followed by anti-digoxigenin conjugated to horseradish peroxidase (NEF832001EA; PerkinElmer, Shanghai, China). Apoptotic cells were recognized as those with brown-stained nuclei.

Transmission electron microscopy (TEM). For electron microscopy, the tissues were fixed as described above and then post-fixed with osmium tetraoxide, dehydrated in a graded ethanol series and embedded in epoxy resin. Samples were sectioned $(50 \mathrm{~nm})$, counterstained with uranyl acetate and lead citrate and observed under a Hitachi H-800 Transmission Electron Microscope (Hitachi, Tokyo, Japan).

Flow cytometric analysis. The effect of simvastatin on the apoptosis of thymocytes was determined by Annexin V-FITC/PI assay in accordance with the manufacturer's instructions provided with the Apoptosis Detection kit (BD Biosciences, San Jose, CA, USA). In brief, thymocytes were incubated with simvastatin $(20 \mu \mathrm{M})$ or vehicle (DMSO) for $3 \mathrm{~h}$ followed by exposure to ${ }^{60} \mathrm{Co} \gamma$-radiation of $8 \mathrm{~Gy}$. At 1 , 6 and $24 \mathrm{~h}$ following exposure, the thymocytes were harvested and washed twice with PBS. Following the addition of FITCAnnexin V (5 $\mu \mathrm{l})$ and PI (5 $\mu \mathrm{l})$ working solutions to the cells, the cell suspension were then incubated at room temperature for $15 \mathrm{~min}$ in the dark and then analyzed usinga flow cytometer (FACSCalibur; BD Biosciences).

Protein extraction and western blot analysis. Tissue/cell protein was extracted as previously described (34). The 
A
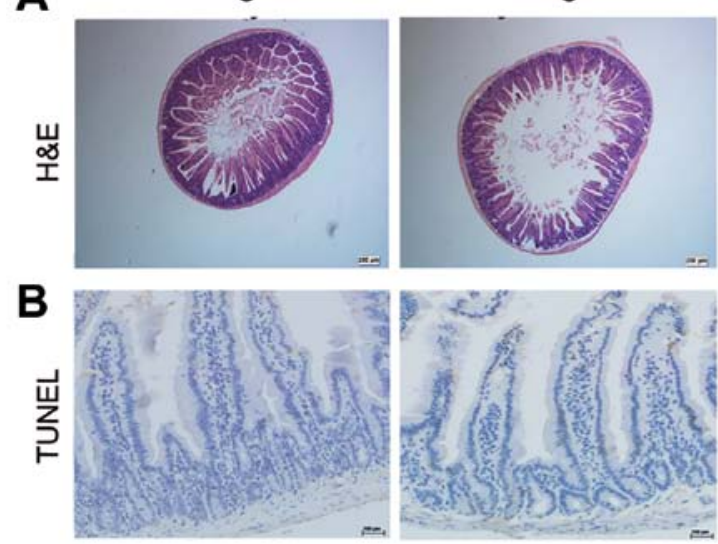

$\mathrm{R}$
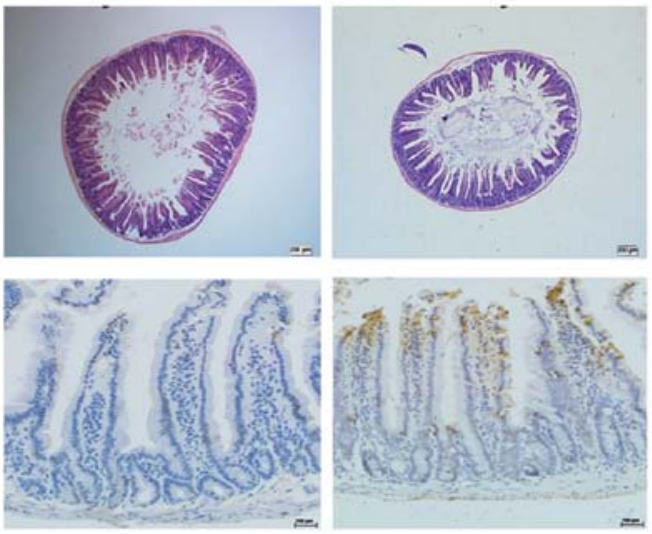

RS
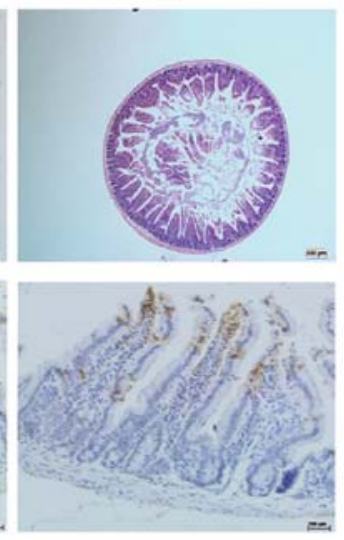
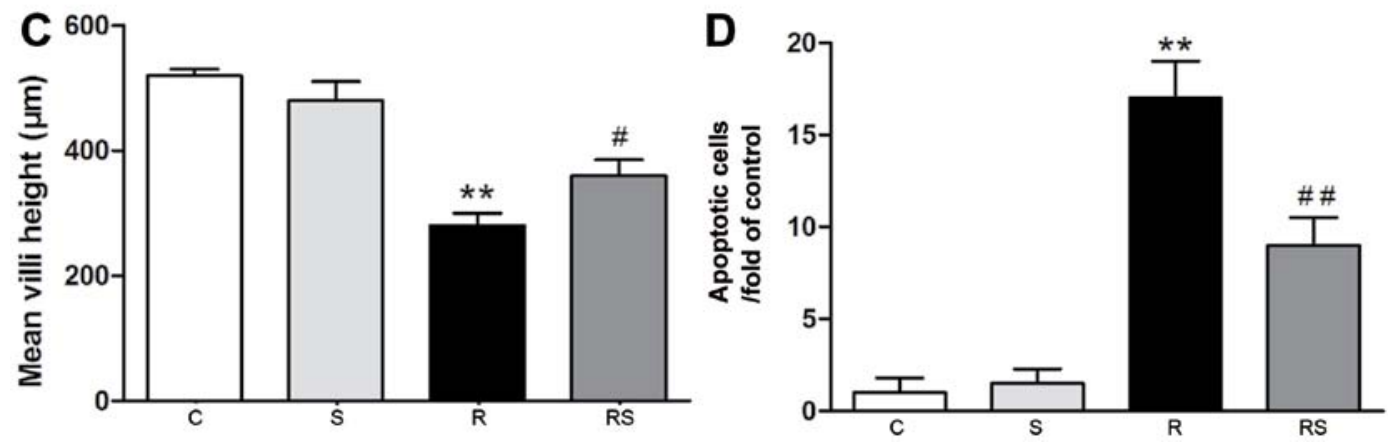

Figure 1. Simvastatin ( $20 \mathrm{mg} / \mathrm{kg} / \mathrm{day})$ significantly protected the intestines of C57BL/6 mice from ionizing radiation. H\&E-stained sections (A) of proximal jejunum obtained 7 days following exposure to 4 Gy radiation. (C) Quantification of mean crypt-villus height is shown ( 30 crypt-villi for each group) (n=10, ${ }^{* *} \mathrm{P}<0.01$ vs. control group; ${ }^{~} \mathrm{P}<0.05$ vs. radiation group). Cell apoptosis in the jejunal sections following irradiation was assessed by TUNEL staining [(B) apoptotic nuclei stained brown and normal nuclei stained blue]. (D) Quantification of TUNEL-positive cells is shown ( $n=10,{ }^{* *} \mathrm{P}<0.01$ vs. C group; ${ }^{\# \#} \mathrm{P}<0.01$ vs. $\mathrm{R}$ group). Values are presented as the means \pm SEM. C, control; S, simvastatin; R, ionizing radiation; RS, radiation + simvastatin.

protein concentration was determined using a BCA Protein assay kit (Beyotime Institute of Biotechnology, Shanghai, China). Samples of approximately $30 \mu \mathrm{g}$ were run on 10 or $12 \%$ sodium dodecyl sulfate-polyacrylamide gel electrophoresis (SDS-PAGE). The proteins were electro-transferred onto nitrocellulose (NC) filter membranes. After blocking, the membranes were incubated with the corresponding primary antibodies for $2 \mathrm{~h}$ at room temperature. The antibodies used were as follows: AKT (\#9272), p53 (1C12 \#2524), PARP (46D11 \#9532) were obtained from Cell Signaling Technology; Bcl-2 (C-2 sc-7382) antibodies were purchased from Santa Cruz Biotechnology, Inc. (Santa Cruz, CA, USA). p-p53 (Ser15 AP068), GAPDH (AG019) and tubulin (AT819) antibodies were obtained from the Beyotime Institute of Biotechnology. Sirtuin 1 (ab75435) antibody used was purchased from Abcam (Cambridge, MA, USA). The membranes were then incubated with IRDye $800 \mathrm{CW}$-conjugated goat anti-rabbit/ mouse secondary antibody (1:5,000; Rockland, Gaithersburg, $\mathrm{MD}, \mathrm{USA}$ ) for $1 \mathrm{~h}$ at $25^{\circ} \mathrm{C}$. The infrared fluorescence image was obtained using an Odyssey infrared imaging system (Li-Cor Bioscience, Lincoln, NE, USA) and the bands were quantified using Quantity One software (Bio-Rad, Hercules, CA, USA).

Statistical analysis. Values are presented as the means \pm SEM. One-way ANOVA was adopted for multiple comparisons involving more than 3 groups, and post hoc comparisons were performed using Neuman-Keuls test. A value of $\mathrm{P}<0.05$ was considered to indicate a statistically significant difference.

\section{Results}

Simvastatin significantly inhibits IR-induced apoptosis in the mouse intestine, bone marrow and thymus. Our previous study reported that IR induced severe damage in the intestines and bones of mice (31). In this study, we found that the damage induced to the intestines and bones of mice by IR was mitigated by simvastatin administration [mean height of villi: C, $520 \pm 10 \mu \mathrm{m} ; \mathrm{S}, 480 \pm 30 \mu \mathrm{m} ; \mathrm{R}, 280 \pm 20 \mu \mathrm{m}$; RS, 360 $\pm 25 \mu \mathrm{m}$ (Fig. 1A and C); intestinal apoptotic cells/ fold of control: C, $1.00 \pm 0.80 ; \mathrm{S}, 1.50 \pm 0.80 ; \mathrm{R}, 17.00 \pm 2.00$; RS, $9.00 \pm 1.50$ (Fig. 1B and D); bone marrow apoptotic cells $/ \%$ :

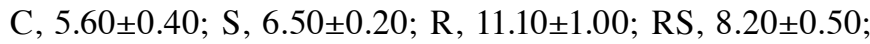
$\mathrm{P}<0.01$ (Fig. 2)].

Cancer patients who undertake radiotherapy could have a compromised function of the immune system (7). Thus, preserving thymus function may be substantially beneficial. In this study, to evaluate the effects of simvastatin on IR-induced damage in the immune system, we examined the change in weight of the thymi and spleens, as well as morphological changes and apoptosis in the mouse thymus 7 days following exposure to IR. IR induced severe weight loss in the spleens and thymi of the mice, as shown in Fig. 3. In addition, the administration of simvastatin slightly alleviated the organ weight loss without statistical significance compared to the controls [thymus/body weight/fold of control: C, 1.00 \pm 0.08 ; S, 1.01 $\pm 0.10 ; \mathrm{R}, 0.23 \pm 0.04 ; \mathrm{RS}, 0.40 \pm 0.02 ; \mathrm{P}<0.01$ vs. control, $\mathrm{P}>0.05$ vs. radiation; spleen/body weight/fold of control: 
A

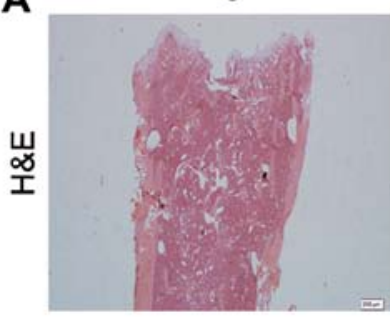

B
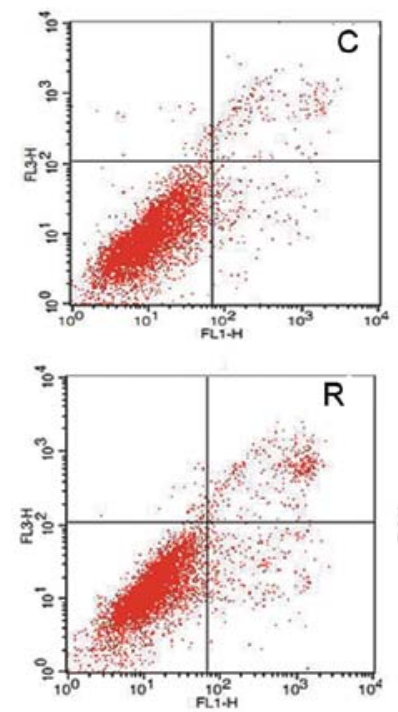

S

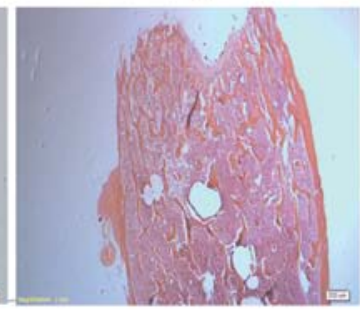

R

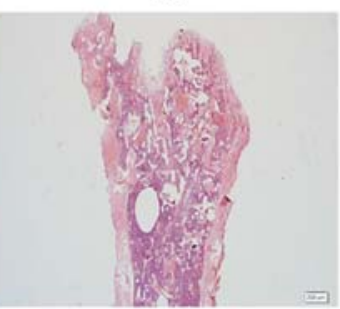

RS

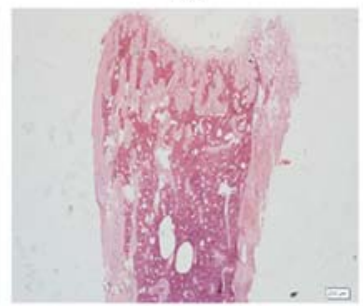

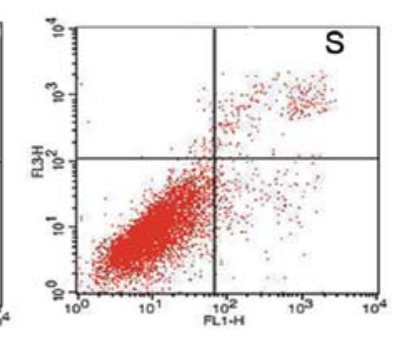

C
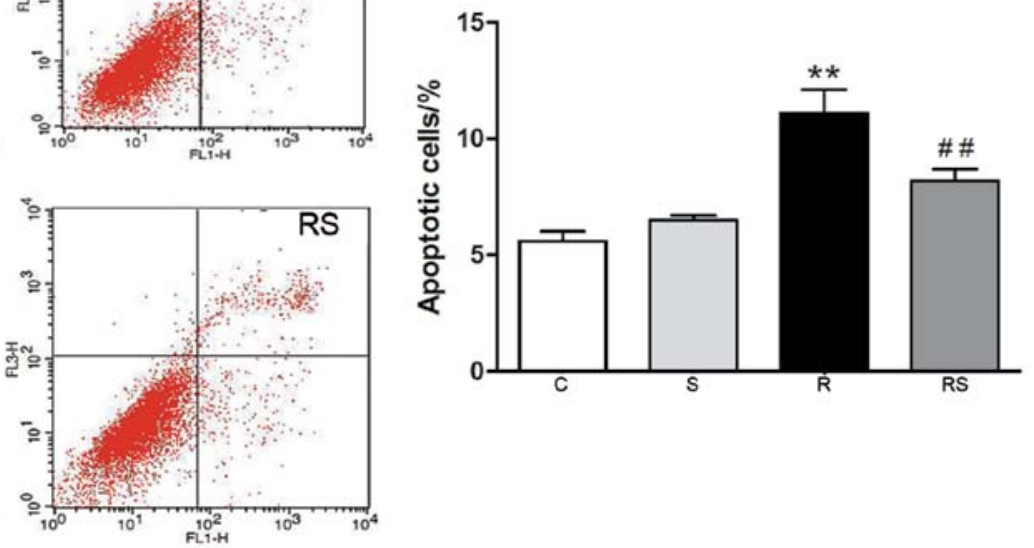

Figure 2. Simvastatin (20 mg/kg/day) significantly inhibits radiation-induced apoptosis in the bone marrow of C57BL/6 mice. Bone marrow samples were procured from the femur 7 days following exposure to $4 \mathrm{~Gy}$ radiation and stained with H\&E (A). The magnification was $\mathrm{x} 4$ and $\mathrm{x} 10$. All bone marrow cells except red blood cells from femurs were stained with Annexin V/PI for the determination of apoptosis. (B) Representative flow charts and (C) statistics showed that the number of apoptotic cells was significantly higher in the radiated mouse bone marrow, which was significantly attenuated by simvastatin treatment. Values are presented as the means \pm SEM ( $n=7,{ }^{* *} \mathrm{P}<0.01$ vs. C group; ${ }^{\# \#} \mathrm{P}<0.01$ vs. R group). C, control; $\mathrm{S}$, simvastatin; $\mathrm{R}$, ionizing radiation; RS, radiation + simvastatin.
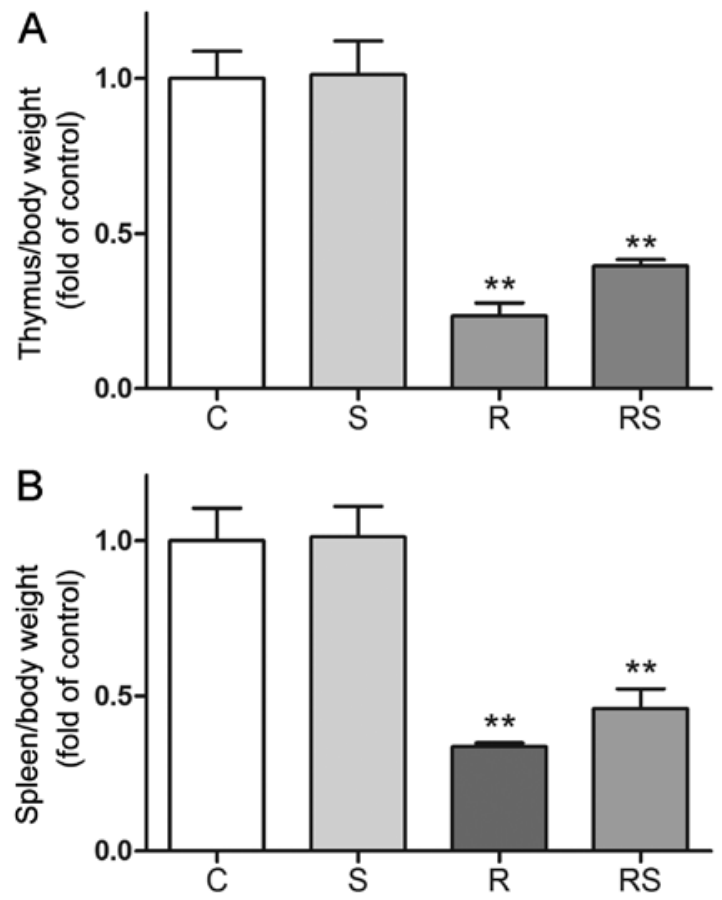

Figure 3. Ionizing radiation at 4 Gy significantly induced weight loss in the (A) mouse thymi and (B) spleens. Simvastatin treatment slightly ameliorated the organ weight loss without any statistical significance compared to the control. Values are means \pm SEM. C, control; S, simvastatin; R, ionizing radiation; radiation + simvastatin $(\mathrm{RS}) . \mathrm{IR}+\operatorname{simvastatin} ; \mathrm{n}=6,{ }^{* * *} \mathrm{P}<0.01$ vs. C group) (One-way ANOVA, Newman-Keuls multiple comparison test).
C, $1.00 \pm 0.10 ; \mathrm{S}, 1.01 \pm 0.10 ; \mathrm{R}, 0.34 \pm 0.01 ; \mathrm{RS}, 0.46 \pm 0.06$; $\mathrm{P}<0.01$ vs. control, $\mathrm{P}>0.05$ vs. radiation (Fig. 3)]. However, TUNEL staining and TEM examination of the mouse thymus indicated that IR induced severe cell apoptosis in the mouse thymus, which was significantly attenuated by pre-treatment with simvastatin [apoptotic cells/fold of control: C, 1.00 \pm 0.19 ; S, 0.38 $\pm 0.22 ; \mathrm{R}, 1.84 \pm 0.36$; RS, 0.68 $\pm 0.12 ; \mathrm{P}<0.01$ (Fig. 4A)].

Radioprotective effects of simvastatin in vivo are related to the AKT/sirtuin 1, and p53/Bcl-2 and PARP pathways. To elucidate the mechanisms through which simvastatin protects the mouse thymus from IR-induced apoptosis, we examined the expression of $\mathrm{p53} / \mathrm{Bcl}-2$, AKT/sirtuin 1 and PARP. It was found that simvastatin alone did not affect the expression of p53/Bcl-2, AKT/sirtuin 1 and PARP compared with the controls. Of note, 3 days following radiation exposure, $\mathrm{p} 53$ expression and phosphorylation significantly increased, and the expression levels of Bcl-2, AKT, sirtuin 1 and PARP were significantly decreased. Importantly, simvastatin treatment significantly inhibited p53 expression and phosphorylation, and increased Bcl-2, AKT, sirtuin 1 and PARP expression in the mice exposed to IR [AKT expression 3 days after radiation/fold of control: C, $1.00 \pm 0.15 ; \mathrm{S}, 0.95 \pm 0.10 ; \mathrm{R}, 0.30 \pm 0.11$; RS, $0.53 \pm 0.13$; p53 expression 3 days after radiation/ fold of control: C, $1.00 \pm 0.29 ; \mathrm{S}, 1.15 \pm 0.12$; R, 2.19 \pm 0.13 ; RS, $1.43 \pm 0.13$; PARP expression 3 days after radiation/

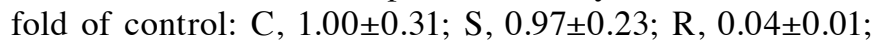



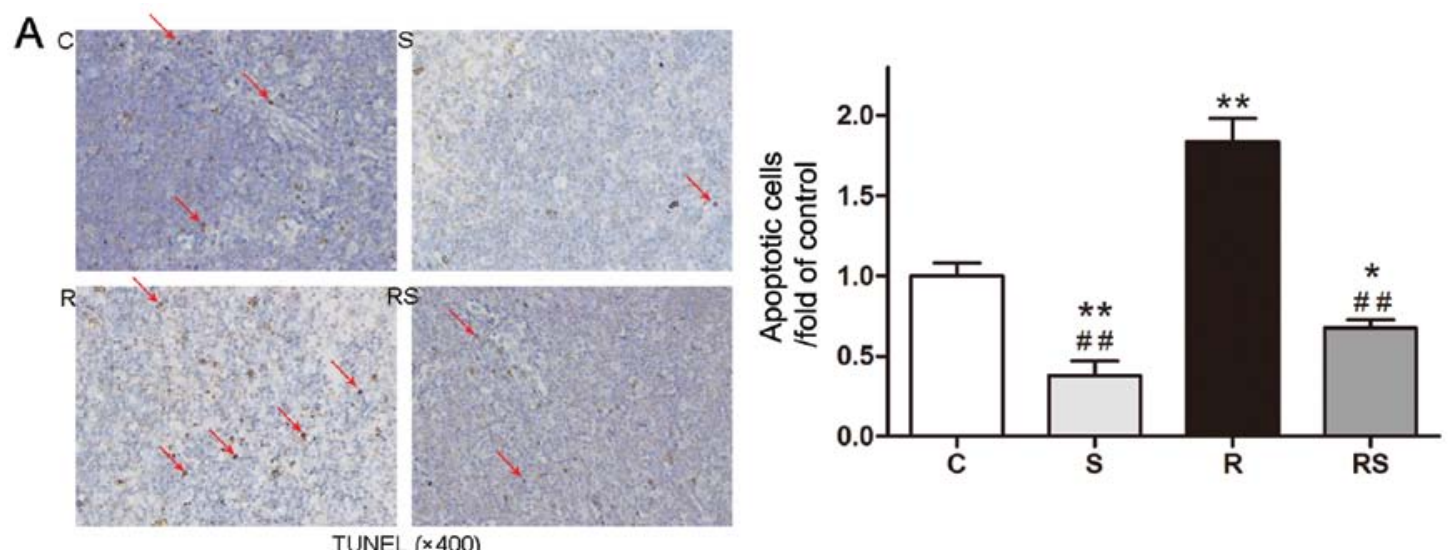

B

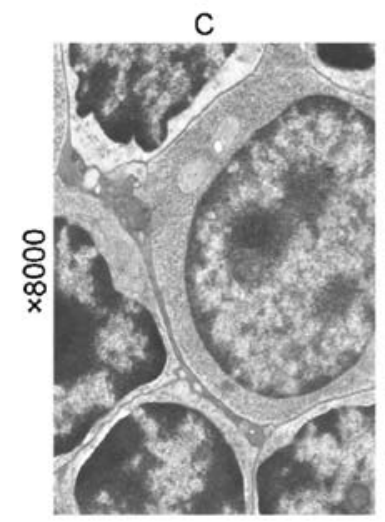

$\mathrm{s}$

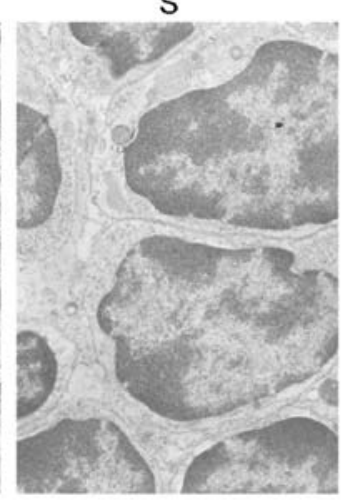

R

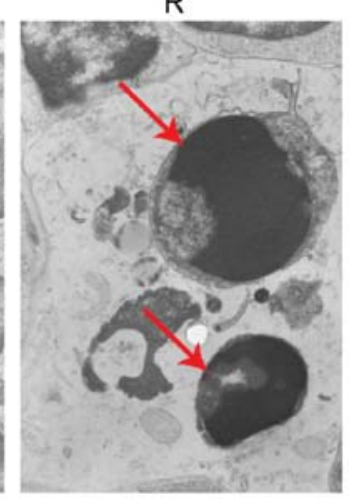

RS

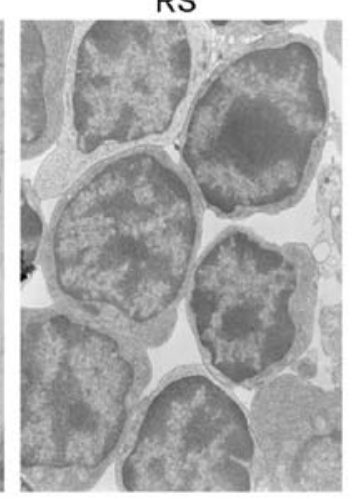

Figure 4. Simvastatin ( $20 \mathrm{mg} / \mathrm{kg} /$ day) significantly attenuates radiation-induced apoptosis in the thymi of C57BL/6 mice. Cell apoptosis in the thymus after irradiation was assessed by TUNEL assay with apoptotic nuclei stained brown and normal nuclei stained blue (A). Magnification, x400. Apoptotic cells were significantly less in the radiation + simvastatin (RS) group compared to $\mathrm{R}$ group (A). Representative electron micrographs taken under $\mathrm{x} 8,000$ magnification indicated that simvastatin ameliorates radiation-induced apoptosis in mice thymi (B). Red arrows indicate apoptotic cells. Values are means \pm SEM. C, control; $\mathrm{S}$, simvastatin; $\mathrm{R}$, ionizing radiation; $\mathrm{RS}, \mathrm{IR}+\operatorname{simvastatin} ; \mathrm{n}=6,{ }^{*} \mathrm{P}<0.05,{ }^{* *} \mathrm{P}<0.01$ vs. C group; ${ }^{\# \#} \mathrm{P}<0.01$ vs. R group (One-way ANOVA, Newman-Keuls multiple comparison test).

RS, 0.41 $\pm 0.21 ; \mathrm{P}<0.01$; quantitative data of protein expression at day 1 and day 7 are not shown (Fig. 5)].

Simvastatin significantly inhibits IR-induced apoptosis of thymocytes in vitro. We adopted Annexin V/PI flow cytometry assay to evaluate thymocyte apoptosis following exposure to IR. It was found that the percentage of viable thymocytes significantly decreased $24 \mathrm{~h}$ after radiation compared to the control, and simvastatin treatment significantly ameliorated radiation-induced apoptosis in thymocytes cultured in vitro

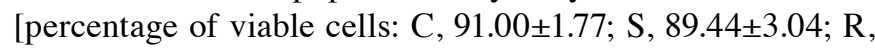
37.45 \pm 2.57 ; RS, 57.37 \pm 1.49 ; $\mathrm{P}<0.01$ (Fig. 6)].

Radioprotective effects of simvastatin on thymocytes are related to the AKT/sirtuin 1 pathway in vitro. To elucidate the mechanisms through which simvastatin protected the thymocytes from radiation damage in vitro, we examined the expression of $\mathrm{p} 53$ / Bcl-2, AKT/sirtuin 1 and PARP at 6 and $24 \mathrm{~h}$ following exposure to IR by western blot analysis. It was found that at 6 and $24 \mathrm{~h}$ after radiation, AKT expression significantly decreased compared to the control, and simvastatin significantly elevated the AKT level compared to the radiation group. The Sirtuin 1 level was significantly lower at 6 and $24 \mathrm{~h}$ when compared to the control, and simvastatin significantly augmented sirtuin 1 expression when compared to the radiation group [AKT

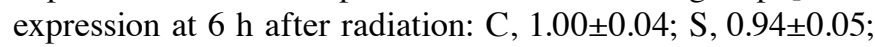

$\mathrm{R}, 0.80 \pm 0.03$; RS, $0.96 \pm 0.05$; AKT expression $24 \mathrm{~h}$ after radia-

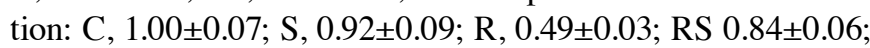
sirtuin 1 expression 6 h after radiation: $C, 1.00 \pm 0.70 ; \mathrm{S}, 1.15 \pm 0.10$; $\mathrm{R}, 0.72 \pm 0.11$; RS, $1.00 \pm 0.13$; sirtuin 1 expression $24 \mathrm{~h}$ after radia-

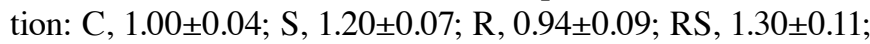
$\mathrm{P}<0.01$ (Fig. 7)]. However, simvastatin treatment did not significantly alter the expression of Bcl-2, p53, phosphorylated p53 and PARP after radiation exposure (quantitative data not shown).

\section{Discussion}

In the present study, the radioprotective effects of pre-treatment with simvastatin were investigated in the mouse thymus and isolated thymocytes cultured in vitro. The main finding was that pre-treatment with simvastatin ameliorated radiationinduced damage to the thymus in vivo and in vitro, which was possibly related to the activation of the AKT/sirtuin 1 pathway.

Statins have been reported to exert pleiotropic effects apart from lowering cholesterol. In particular, statins have been shown to be effective in protecting normal tissue from radiation-induced damage (1,31-34). Ostrau et al reported that lovastatin attenuated IR-induced normal tissue damage in vivo (35). We previously reported that simvastatin attenuated radiation-induced tissue damage in mice (31). Mathew et al demonstrated that simvastatin attenuated radiation-induced murine lung injury and dysregulated lung gene expression (32). 
A

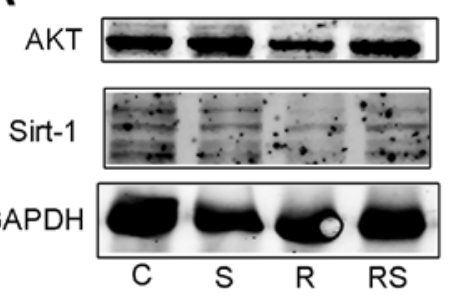

B

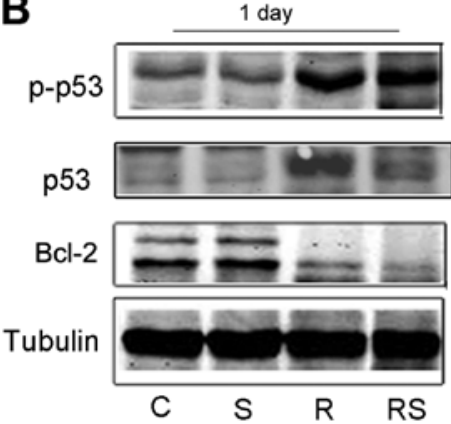

C

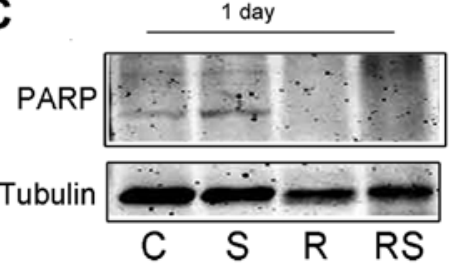

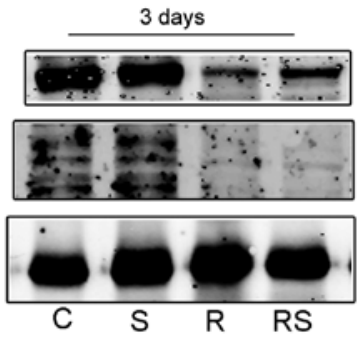

3 days

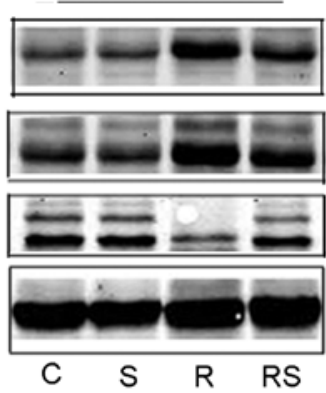

3 days

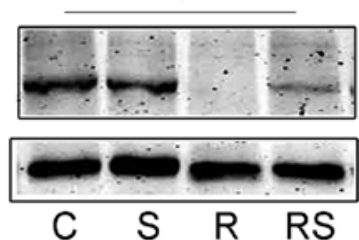

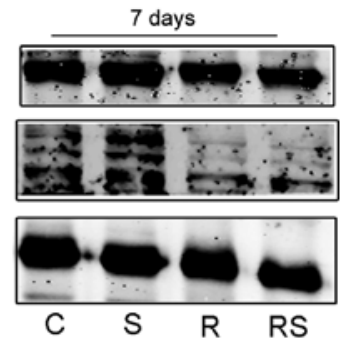

7 days
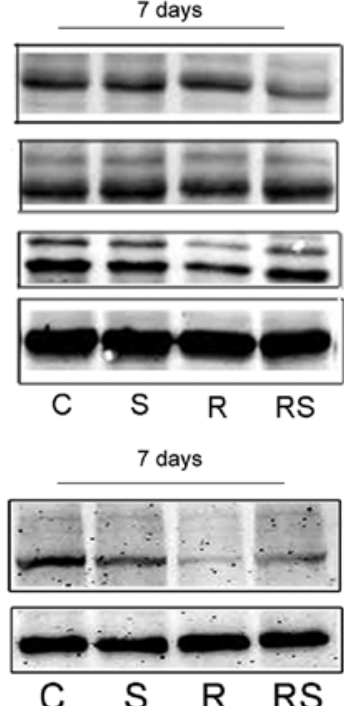
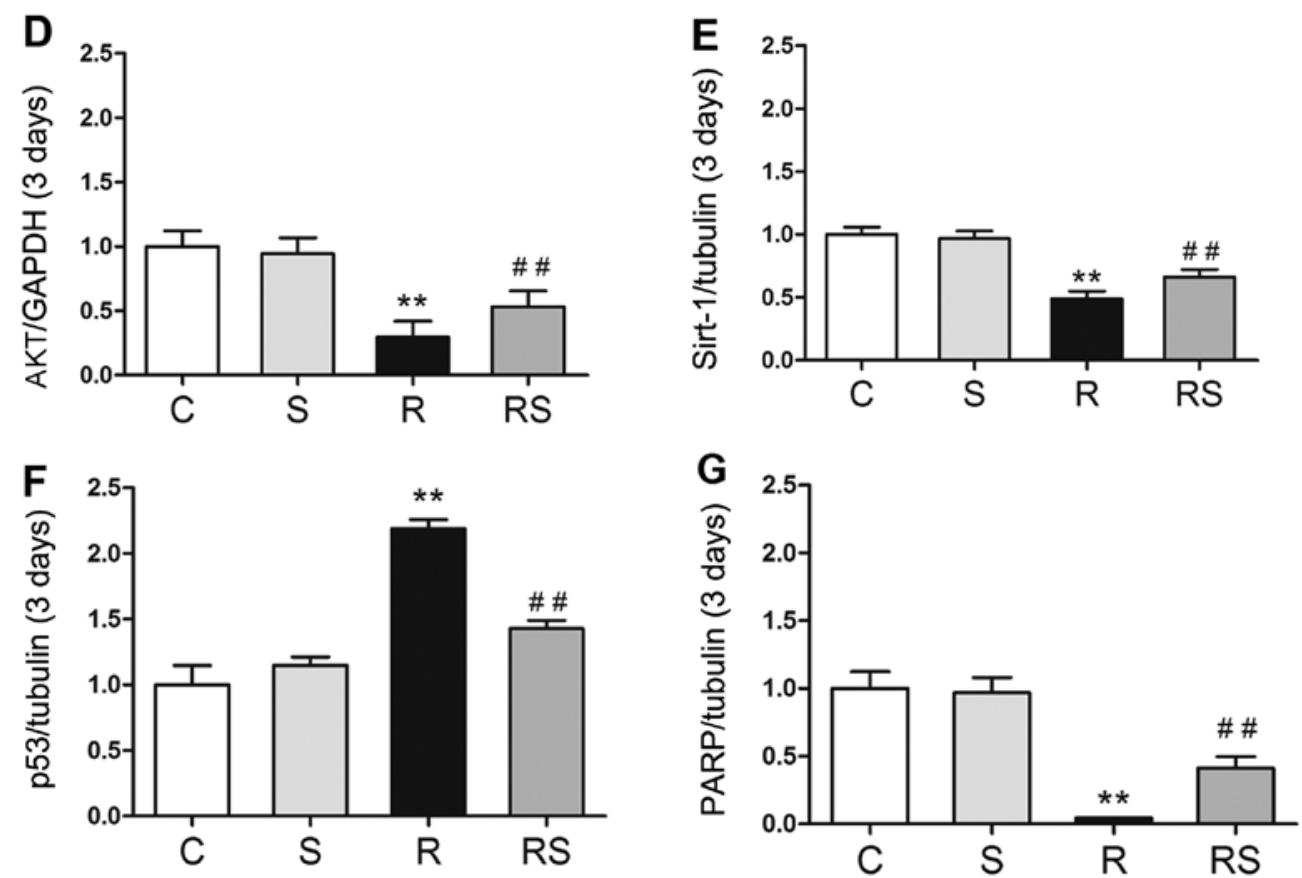

Figure 5. Radioprotective effects of simvastatin on mouse thymi after radiation are related to p53 expression/ phosphorylation (B) and AKT/sirtuin 1 (A), poly(ADP-ribose) polymerase (PARP) expression (C) in vivo. (D-G) The quantitative results of AKT, sirtuin 1, p53 and PARP expression 3 days after radiation are shown. At 3 days after irradiation, the expression of (D) AKT, (E) sirtuin 1 and (G) PARP was significantly decreased in the radiated mouse thymus, while simvastatin significantly augmented their expression. (F) Compared to the radiated group, p53 expression was significantly suppressed by simvastatin (F). Values are the means \pm SEM. C, control; S, simvastatin; R, ionizing radiation; radiation + simvastatin $(\mathrm{RS}), \mathrm{IR}+\operatorname{simvastatin} ; \mathrm{n}=6,{ }^{* * *} \mathrm{P}<0.01 \mathrm{vs}$. C group; ${ }^{\# \#} \mathrm{P}<0.01$ vs. $\mathrm{R}$ group (One-way ANOVA, Newman-Keuls multiple comparison test).

Lowe et al demonstrated that $\mathrm{p} 53$ was required for the radiation-induced apoptosis of mouse thymocytes (9). The activation of p53 facilitates apoptosis, autophagy etc. in response to radiation (36-38). The present study showed that the levels of both p53 and p-p53 were significantly increased in mice following exposure to radiation. Radiation increases cell death, DNA fragmentation, downregulates $\mathrm{Bcl}-2$ and upregulates $\mathrm{Bcl}-2$ associated X protein (Bax) $(39,40)$. It has been reported that radiation-induced DNA double-strand breaks can promote $\mathrm{p} 53$ activation, and Bcl-2-overexpressing cells have a higher survival 

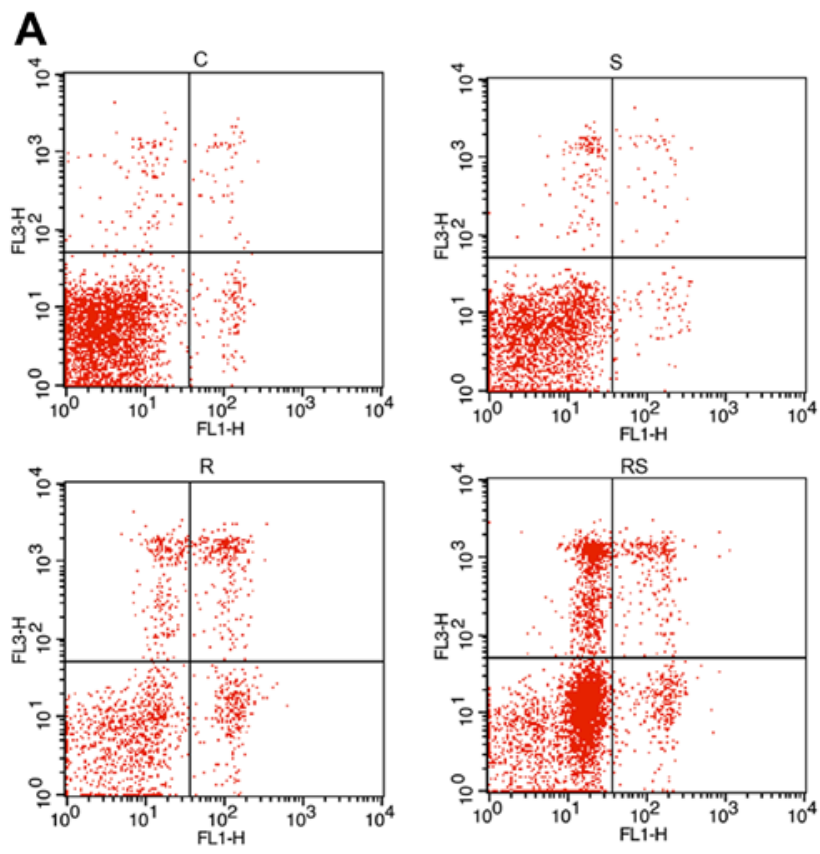

B

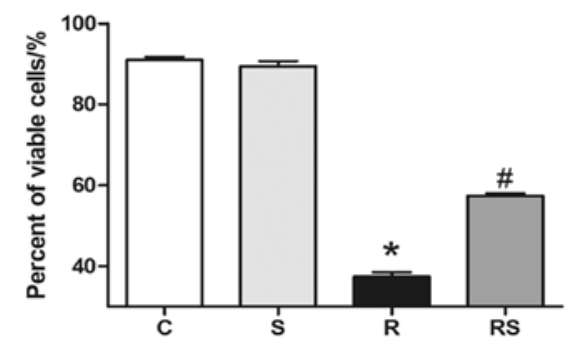

Figure 6. Representative (A) flow cytometry charts and (B) statistics showed that simvastatin $(20 \mu \mathrm{M})$ significantly inhibited the radiation-induced apoptosis of thymocytes cultured in vitro. Values are the means \pm SEM. C, control; $\mathrm{S}$, simvastatin; $\mathrm{R}$, ionizing radiation; radiation + simvastatin ( $\mathrm{RS}), \mathrm{IR}+\mathrm{sim}$ vastatin; $n=6,{ }^{*} \mathrm{P}<0.05$ vs. $\mathrm{C}$ group; ${ }^{\#} \mathrm{P}<0.05$ vs. $\mathrm{R}$ group (One-way ANOVA, Newman-Keuls multiple comparison test). rate (41). In neoplasms, mutation of the p53 tumor suppressor or overexpression of pro-survival Bcl-2, is a key step toward malignant transformation and therapeutic resistance (42). It has been demonstrated that reducing the affinity of p53 to the antiapoptotic protein, Bcl-2, reduces the radiosensitivity of normal tissue (43). The present study found that simvastatin not only inhibited p53 expression and activation, but also increased the $\mathrm{Bcl}-2$ level. These findings demonstrate that the radioprotective effects of simvastatin are at least partially related to the p53/ Bcl-2 pathway in mice.

AKT signaling regulates cellular processes, including proliferation, invasion and apoptosis (44). AKT suppresses DNA damage processing and checkpoint activation in late the G2 phase after radiation (45). Edwards et al demonstrated that AKT in the tumor vascular endothelium plays an important role in enhancing the efficacy of IR (18). An in vitro study indicated that the activation of AKT results in reduced Bax translocation to the mitochondria, inhibiting apoptosis (46). Sirtuin 1 is an important regulator of radiation-induced cellular senescence (47). It has been demonstrated that resveratrol, an activator of sirtuin 1, inhibits apoptosis induced by radiation by effectively antagonizing oxidation (48). In addition, recent studies demonstrate that targeted silencing of sirtuin 1 expression may be beneficial by promoting p53-induced apoptosis in cancer cells, and by sensitizing cancerous cells to radiation therapy (49). In this study, we found that the expression of AKT and sirtuin 1 was decreased by radiation and augmented by simvastatin pre-treatment in the mouse thymus and in cultured thymocytes. In addition, AKT has been reported to be related to sirtuin 1. Gao et al reported that sirtuin 1 was upregulated through the AKT signaling pathway in the proliferation and migration of endothelial cells (50). It has also been found that the PI3K-AKT-GSK3 $\beta$ signaling pathway is required for sirtuin 1 induction by endoplasmic reticulum stress (51). However, Ge et al showed that sirtuin 1 knockdown attenuated
A
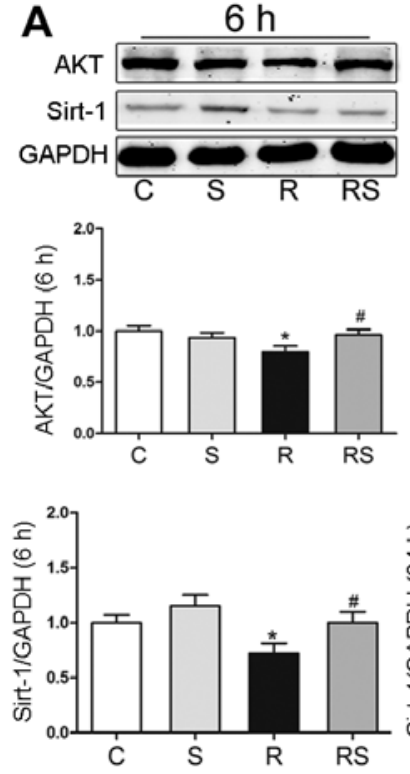

$24 \mathrm{~h}$
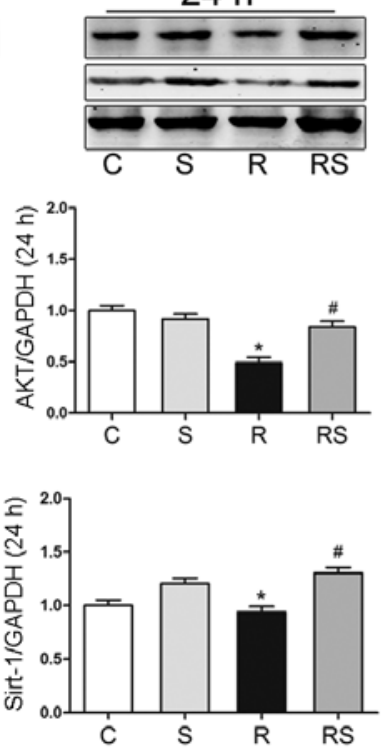

B

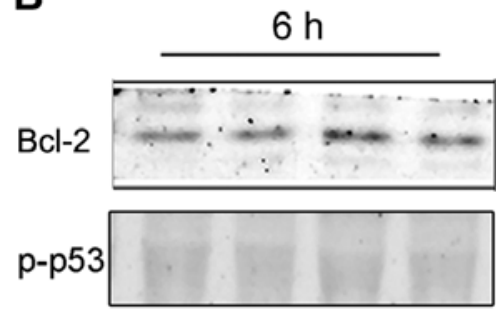

p53
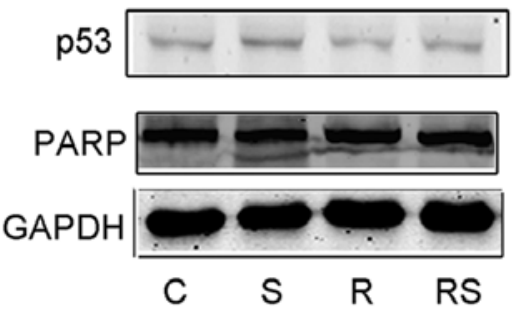

$24 \mathrm{~h}$
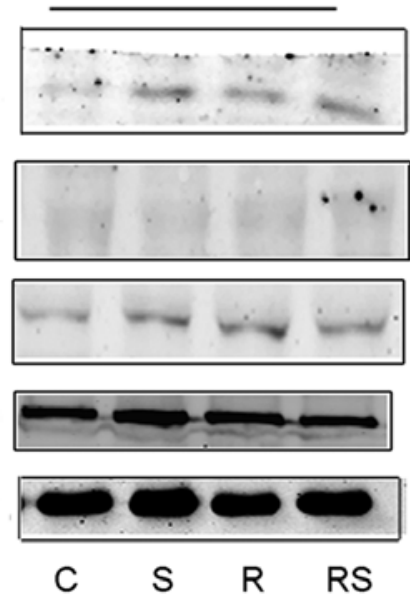

Figure 7. Representative western blots and statistics (A) showed that AKT/sirtuin 1 expression significantly increased in the simvastatin-pre-treated cells 6 and $24 \mathrm{~h}$ after radiation in vitro. The expression of B-cell lymphoma-2 (Bcl-2), p53, poly(ADP-ribose) polymerase (PARP) expression and p53 phosphorylation was not significantly altered following radiation and simvastatin treatment (B). Values are the means \pm SEM. C, control; S, simvastatin; R, ionizing radiation; radiation + simvastatin $(\mathrm{RS}), \mathrm{IR}+\operatorname{simvastatin} ; \mathrm{n}=6,{ }^{*} \mathrm{P}<0.05$ vs. $\mathrm{C}$ group; ${ }^{\text {"P }} \mathrm{P}<0.05$ vs. $\mathrm{R}$ group (One-way ANOVA, Newman-Keuls multiple comparison test). 
PPAR- $\gamma$ dependent AKT activation in HepG2 cells (52). In summary, it is suggested that AKT/sirtuin 1 may be involved in the radioprotective effects of simvastatin.

PARP is also closely linked to apoptosis. Jeffrey et al demonstrated that the inhibition of PARP enhanced the efficacy of radiation (26). Bryant et al and others have also reviewed the potential of PARP inhibitors as antitumor agents $(28,53)$. PARP-1 activity is essential in the upstream regulation of radiation-induced $\mathrm{NF}-\kappa \mathrm{B}$ activation (27). Consistent with this, the present study demonstrated that simvastatin upregulated PARP expression in the thymi of mice exposed to radiation.

Our in vitro experiments also found that simvastatin treatment significantly increased the survival of thymocytes exposed to radiation. In this study, we did not find that simvastatin treatment altered $\mathrm{p} 53 / \mathrm{Bcl}-2$ and PARP expression in cultured thymocytes. IR induces complex physiological signaling modifications. However, the above-mentioned reaction was dependent of the whole-function intactness of the organism exposed to irradiation. The results of the present study showed that IR significantly altered AKT/sirtuin 1 expression, but not that of p53, Bcl-2 and PARP, implying that the AKT/sirtuin 1 signaling pathway is dominant in the in vitro post-irradiation reaction. Yu and Little from the Harvard School of Public Health also proved that in three human lymphoblast cell lines, the p53/Bcl-2 pathway was not required for IR-induced apoptosis (54), which coincided with our findings.

In conclusion, the present study demonstrated that simvastatin pre-treatment attenuated radiation-induced damage to the thymus in mice possibly by activating the AKT/sirtuin 1 pathway.

\section{Acknowledgements}

The present study was supported by the National Major Special Foundation of China (no. 2013ZX09J13110-07B).

\section{References}

1. Wang J, Boerma M, Fu Q, Kulkarni A, Fink LM and Hauer-Jensen M: Simvastatin ameliorates radiation enteropathy development after localized, fractionated irradiation by a protein $\mathrm{C}$-independent mechanism. Int J Radiat Oncol Biol Phys 68 : 1483-1490, 2007.

2. Christiansen H, Saile B, Neubauer-Saile K, Tippelt S, Rave-Fränk M, Hermann RM, Dudas J, Hess CF, Schmidberger H and Ramadori G: Irradiation leads to susceptibility of hepatocytes to TNF-alpha mediated apoptosis. Radiother Oncol 72: 291-296, 2004

3. Stewart FA and Dörr W: Milestones in normal tissue radiation biology over the past 50 years: From clonogenic cell survival to cytokine networks and back to stem cell recovery. Int J Radiat Biol 85: 574-586, 2009.

4. Kolesnick R and Fuks Z: Radiation and ceramide-induced apoptosis. Oncogene 22: 5897-5906, 2003.

5. Okunieff P, Chen Y, Maguire DJ and Huser AK: Molecular markers of radiation-related normal tissue toxicity. Cancer Metastasis Rev 27: 363-374, 2008.

6. Kim Y and He YY: Ultraviolet radiation-induced non-melanoma skin cancer: Regulation of DNA damage repair and inflammation. Genes Dis 1: 188-198, 2014

7. Najafi M, Fardid R, Hadadi G and Fardid M: The mechanisms of radiation-induced bystander effect. J Biomed Phys Eng 4: 163-172, 2014

8. Stoecklein VM, Osuka A, Ishikawa S, Lederer MR, WankeJellinek L and Lederer JA: Radiation exposure induces inflammasome pathway activation in immune cells. J Immunol 194: $1178-1189,2015$.
9. Lowe SW, Schmitt EM, Smith SW, Osborne BA and Jacks T: p53 is required for radiation-induced apoptosis in mouse thymocytes. Nature 362: 847-849, 1993.

10. May P and May E: Twenty years of p53 research: Structural and functional aspects of the p53 protein. Oncogene 18: 7621-7636, 1999.

11. McBride OW, Merry D and Givol D: The gene for human p53 cellular tumor antigen is located on chromosome 17 short arm (17p13). Proc Natl Acad Sci USA 83: 130-134, 1986.

12. Tjalma WA, Weyler JJ, Bogers JJ, Pollefliet C, Baay M, Goovaerts GC, Vermorken JB, van Dam PA, van Marck EA and Buytaert PM: The importance of biological factors (Bcl-2, bax, p53, PCNA, MI, HPV and angiogenesis) in invasive cervical cancer. Eur J Obstet Gynecol Reprod Biol 97: 223-230, 2001.

13. Cleary ML, Smith SD and Sklar J: Cloning and structural analysis of cDNAs for Bcl-2 and a hybrid Bcl-2/immunoglobulin transcript resulting from the $\mathrm{t}(14 ; 18)$ translocation. Cell 47: 19-28, 1986.

14. Tsujimoto Y, Finger LR, Yunis J, Nowell PC and Croce CM: Cloning of the chromosome breakpoint of neoplastic B cells with the $t(14 ; 18)$ chromosome translocation. Science 226: 1097-1099, 1984.

15. Adán N, Guzmán-Morales J, Ledesma-Colunga MG, PeralesCanales SI, Quintanar-Stéphano A, López-Barrera F, Méndez I, Moreno-Carranza B, Triebel J, Binart N, et al: Prolactin promotes cartilage survival and attenuates inflammation in inflammatory arthritis. J Clin Invest 123: 3902-3913, 2013.

16. Follis AV, Llambi F, Ou L, Baran K, Green DR and Kriwacki RW: The DNA-binding domain mediates both nuclear and cytosolic functions of p53. Nat Struct Mol Biol 21: 535-543, 2014.

17. Li HF, Kim JS and Waldman T: Radiation-induced Akt activation modulates radioresistance in human glioblastoma cells. Radiat Oncol 4: 43, 2009.

18. Edwards E, Geng L, Tan J, Onishko H, Donnelly E and Hallahan DE: Phosphatidylinositol 3-kinase/Akt signaling in the response of vascular endothelium to ionizing radiation. Cancer Res 62: 4671-4677, 2002.

19. Chen WS, Xu PZ, Gottlob K, Chen ML, Sokol K, Shiyanova T, Roninson I, Weng W, Suzuki R, Tobe K, et al: Growth retardation and increased apoptosis in mice with homozygous disruption of the Akt1 gene. Genes Dev 15: 2203-2208, 2001.

20. Li X, Zhang KY, Zhang P, Chen LX, Wang L, Xie M, Wang CY and Tang XQ: Hydrogen sulfide inhibits formaldehyde-induced endoplasmic reticulum stress in $\mathrm{PC} 12$ cells by upregulation of SIRT-1. PLoS One 9: e89856, 2014.

21. Pillai VB, Sundaresan NR and Gupta MP: Regulation of Akt signaling by sirtuins: Its implication in cardiac hypertrophy and aging. Circ Res 114: 368-378, 2014.

22. Wang Q, Sun X, Li X, Dong X, Li P and Zhao L: Resveratrol attenuates intermittent hypoxia-induced insulin resistance in rats: Involvement of Sirtuin 1 and the phosphatidylinositol-4,5-bisphosphate 3-kinase/AKT pathway. Mol Med Rep 11: 151-158, 2015.

23. Isabelle M, Moreel X, Gagné JP, Rouleau M, Ethier C, Gagné $P$, Hendzel MJ and Poirier GG: Investigation of PARP-1, PARP-2, and PARG interactomes by affinity-purification mass spectrometry. Proteome Sci 8: 22, 2010.

24. Yu SW, Andrabi SA, Wang H, Kim NS, Poirier GG, Dawson TM and Dawson VL: Apoptosis-inducing factor mediates poly(ADP-ribose) (PAR) polymer-induced cell death. Proc Natl Acad Sci USA 103: 18314-18319, 2006.

25. Lindahl T, Satoh MS, Poirier GG and Klungland A: Posttranslational modification of poly(ADP-ribose) polymerase induced by DNA strand breaks. Trends Biochem Sci 20: 405-411, 1995.

26. Albert JM, Cao C, Kim KW, Willey CD, Geng L, Xiao D, Wang H, Sandler A, Johnson DH, Colevas AD, et al: Inhibition of poly(ADP-ribose) polymerase enhances cell death and improves tumor growth delay in irradiated lung cancer models. Clin Cancer Res 13: 3033-3042, 2007.

27. Veuger SJ, Hunter JE and Durkacz BW: Ionizing radiationinduced NF-kappaB activation requires PARP-1 function to confer radioresistance. Oncogene 28: 832-842, 2009.

28. Bryant HE and Helleday T: Poly(ADP-ribose) polymerase inhibitors as potential chemotherapeutic agents. Biochem Soc Trans 32: 959-961, 2004.

29. Lopez-Pedrera C, Ruiz-Limon P, Valverde-Estepa A, Barbarroja N and Rodriguez-Ariza A: To cardiovascular disease and beyond: New therapeutic perspectives of statins in autoimmune diseases and cancer. Curr Drug Targets 13: 829-841, 2012.

30. Fritz G, Henninger $C$ and Huelsenbeck J: Potential use of HMG-CoA reductase inhibitors (statins) as radioprotective agents. Br Med Bull 97: 17-26, 2011. 
31. Zhao X, Yang H, Jiang G, Ni M, Deng Y, Cai J, Li Z, Shen F and Tao X: Simvastatin attenuates radiation-induced tissue damage in mice. J Radiat Res (Tokyo) 55: 257-264, 2014.

32. Mathew B, Huang Y, Jacobson JR, Berdyshev E, Gerhold LM, Wang T, Moreno-Vinasco L, Lang G, Zhao Y, Chen CT, et al: Simvastatin attenuates radiation-induced murine lung injury and dysregulated lung gene expression. Am J Respir Cell Mol Biol 44: 415-422, 2011.

33. Lacerda L, Reddy JP, Liu D, Larson R, Li L, Masuda H, Brewer T, Debeb BG, Xu W, Hortobágyi GN, et al: Simvastatin radiosensitizes differentiated and stem-like breast cancer cell lines and is associated with improved local control in inflammatory breast cancer patients treated with postmastectomy radiation. Stem Cells Transl Med 3: 849-856, 2014.

34. Oh DS, Koontz B, Freedland SJ, Gerber L, Patel P, Lewis S, Yoo DS, Oleson J and Salama JK: Statin use is associated with decreased prostate cancer recurrence in men treated with brachytherapy. World J Urol 33: 93-97, 2015.

35. Ostrau C, Hülsenbeck J, Herzog M, Schad A, Torzewski M, Lackner KJ and Fritz G: Lovastatin attenuates ionizing radiationinduced normal tissue damage in vivo. Radiother Oncol 92: 492-499, 2009

36. Choi DW, Na W, Kabir MH, Yi E, Kwon S, Yeom J, Ahn JW, Choi HH, Lee Y, Seo KW, et al: WIP1, a homeostatic regulator of the DNA damage response, is targeted by HIPK2 for phosphorylation and degradation. Mol Cell 51: 374-385, 2013.

37. Contreras AU, Mebratu Y, Delgado M, Montano G, Hu CA Ryter SW, Choi AM, Lin Y, Xiang J, Chand H, et al: Deacetylation of p53 induces autophagy by suppressing Bmf expression. J Cell Biol 201: 427-437, 2013.

38. Xie L, Pi X, Mishra A, Fong G, Peng J and Patterson C: PHD3-dependent hydroxylation of HCLK 2 promotes the DNA damage response. J Clin Invest 122: 2827-2836, 2012.

39. Oltersdorf T, Elmore SW, Shoemaker AR, Armstrong RC, Augeri DJ, Belli BA, Bruncko M, Deckwerth TL, Dinges J, Hajduk PJ, et al: An inhibitor of Bcl-2 family proteins induces regression of solid tumours. Nature 435: 677-681, 2005

40. Wang XY, Ma ZC, Wang YG, Tan HL, Xiao CR, Liang QD, Tang XL, Cheng Y and Gao Y: Tetramethylpyrazine protects lymphocytes from radiation-induced apoptosis through nuclear factor- $\kappa$ B. Chin J Nat Med 12: 730-737, 2014

41. Milyavsky M, Gan OI, Trottier M, Komosa M, Tabach O, Notta F, Lechman E, Hermans KG, Eppert K, Konovalova Z, et al: A distinctive DNA damage response in human hematopoietic stem cells reveals an apoptosis-independent role for $\mathrm{p} 53$ in selfrenewal. Cell Stem Cell 7: 186-197, 2010.

42. Sidi S, Sanda T, Kennedy RD, Hagen AT, Jette CA, Hoffmans R, Pascual J, Imamura S, Kishi S, Amatruda JF, et al: Chk1 suppresses a caspase-2 apoptotic response to DNA damage that bypasses p53, Bcl-2, and caspase-3. Cell 133: 864-877, 2008.
43. Strom E, Sathe S, Komarov PG, Chernova OB, Pavlovska I, Shyshynova I, Bosykh DA, Burdelya LG, Macklis RM, Skaliter R, et al: Small-molecule inhibitor of p53 binding to mitochondria protects mice from gamma radiation. Nat Chem Biol 2: 474-479, 2006.

44. Bussink J, van der Kogel AJ and Kaanders JH: Activation of the PI3-K/AKT pathway and implications for radioresistance mechanisms in head and neck cancer. Lancet Oncol 9: 288-296, 2008.

45. Xu N, Hegarat N, Black EJ, Scott MT, Hochegger H and Gillespie DA: Akt/PKB suppresses DNA damage processing and checkpoint activation in late G2. J Cell Biol 190: 297-305, 2010.

46. Tessner TG, Muhale F, Riehl TE, Anant S and Stenson WF: Prostaglandin E2 reduces radiation-induced epithelial apoptosis through a mechanism involving AKT activation and bax translocation. J Clin Invest 114: 1676-1685, 2004.

47. Hong EH, Lee SJ, Kim JS, Lee KH, Um HD, Kim JH, Kim SJ, Kim JI and Hwang SG: Ionizing radiation induces cellular senescence of articular chondrocytes via negative regulation of SIRT1 by p38 kinase. J Biol Chem 285: 1283-1295, 2010.

48. Li J, Feng L, Xing Y, Wang Y, Du L, Xu C, Cao J, Wang Q, Fan S, Liu Q, et al: Radioprotective and antioxidant effect of resveratrol in hippocampus by activating Sirt1. Int J Mol Sci 15: 5928-5939, 2014.

49. Nerurkar PV and Nerurkar VR: Can Sir(2) regulate cancer? Cellscience 4: 50-56, 2008.

50. Gao Z, Wang H, Xiao FJ, Shi XF, Zhang YK, Xu QQ, Zhang XY, Ha XQ and Wang LS: SIRT1 mediates Sphk1/S1P-induced proliferation and migration of endothelial cells. Int J Biochem Cell Biol 74: 152-160, 2016.

51. Koga T, Suico MA, Shimasaki S, Watanabe E, Kai Y, Koyama K, Omachi K, Morino-Koga S, Sato T, Shuto T, et al: Endoplasmic Reticulum (ER) Stress Induces Sirtuin 1 (SIRT1) Expression via the PI3K-Akt-GSK3 $\beta$ Signaling Pathway and Promotes Hepatocellular Injury. J Biol Chem 290: 30366-30374, 2015.

52. Ge Z, Zhang P, Hong T, Tang S, Meng R, Bi Y and Zhu D: Erythropoietin alleviates hepatic insulin resistance via PPAR $\gamma$ dependent AKT activation. Sci Rep 5: 17878, 2015.

53. Kotsopoulos IC, Kucukmetin A, Mukhopadhyay A, Lunec J and Curtin NJ: Poly(ADP-Ribose) polymerase in cervical cancer pathogenesis: Mechanism and potential role for PARP inhibitors. Int J Gynecol Cancer 26: 763-769, 2016.

54. Yu Y and Little JB: p53 is involved in but not required for ionizing radiation-induced caspase- 3 activation and apoptosis in human lymphoblast cell lines. Cancer Res 58: 4277-4281, 1998. 